gigantic armadilloes which in past geological epochs were so abundant in Southern Brazil. The little Chlamydophorus truncatus is, we believe, mainly, if not entirely, subterranean in its habits. May there not still exist a larger representative of the same or nearly allied genus, or, if the suggestion be not too bold, even a last descendant of the Glyptodonts?

SUN-SPOTS AND DECLINATION RANGES

$\mathrm{THE}$ excellent article by $\mathrm{Mr}$. Broun in a recent number of NATURE puts before us in a very clear manner the strong grounds that we have for believing in a true connection between sun-spots and terrestrial magnetism. If the argument were not already sufficiently powerful it might be yet further strengthened by bearing in mind that not merely do the most prominent inequalities march tozether in these two phenomena but the correspondence exiends likewise to those waves of shorter period that ride as it were on the back of the longer ones. In a paper which is now before the Royal Society I have shown this intimacy of correspondence by comparing together the sun-spot and declination range records for the cycle extending from the minimum of 1855 to that of 1867 . All the prominent sun-spot waves are reproduced by magnetic declination waves, the latter, however, invariably lagging behind the former.

Then with regard to the long period cycle under discussion I make it to begin for sun-spots with September $I_{5}$, 1855, which was a minimum point, and to end with March I 5, I 867, which was another minimum point. On the other hand the corresponding cycle for declination range begins with February 15,1856 , and ends with August 15,1867 . Thus the length of period is the same in both; the magnetic cycle lagging, however, five months behind that for sun-spots.

I may also mention that I am at present comparing together the Prague declination ranges with the sun-spot curve determined from Hofrath Schwabe's observations, and although the comparison is not finished, I believe that this lagging behind will form a prominent feature of the results. Further back than Schwabe we cannot go, as the sun-spot records are not sufficiently accurate for this kind of work.

I am not sure, however, that I quite agree with $\mathrm{Mr}$. Broun when he says "no doubt the admission of the existence of a causal connection between the two phenomena is opposed to the hypothesis, which many other facts render wholly untenable, that the magnetic variations are due to the heating action of the sun."

As far as sun-spots and declination ranges are concerned, what are the facts regarding the connection between them? These are two in number. In the first place, all the considerable oscillations of the sun-spots are reproduced in the declination-ranges. Secondly, the reproductions in the declination-ranges lag, it appears, behind the corresponding sun-spot waves. This latter fact strikes me as being rather in favour of the view which regards declination-ranges to be (like temperature-ranges) in some way the result of an influence from the sun which is of the nature of an emanation or radiation. But I will not press the point except to remark that this and a host of other questions, some of them of great importance, must wait for their solution until we shall have obtained a sufficiently complete and continuous record of solar activity, and along with it an equally complete and continuous record of the radiant power of the sun.

From the observatories already established, we have a reasonable prospect of receiving good magnetical information, and there is abundance of meteorological activity, but it is nearly, if not absolutely, impossible, from the observations already made, to tell whether the sun be hotter or colder as a whole, when there are most spots on his surface. The sooner we get to know this the better for our problem.

\section{THE ISLANDS OF ST. PAUL AND AMSTERDAM}

$A \mathrm{~S}$ is now well known, a French expedition visited these islands towards the close of 1874 for the purpose of watching the transit of Venus across the sun on December 9 of that year. M. G. de l'Isle accompanied the expedition as botanist; Dr. Rochefort, with M. Vélain to assist him, were to look after the zoological and geological departments. M. Vélain, who was a pupil of Prof Lacaze-Duthiers has just published, in the Archives de Zoologie Expérimentale et Générale (tome 6, 1877), a mos interesting account of these islands and their fauna, with in addition, a very detailed account of the collections of shells made. We are indebted $t 0$ the extreme kindness of M. Vélain for the excellent illustrations which accom-

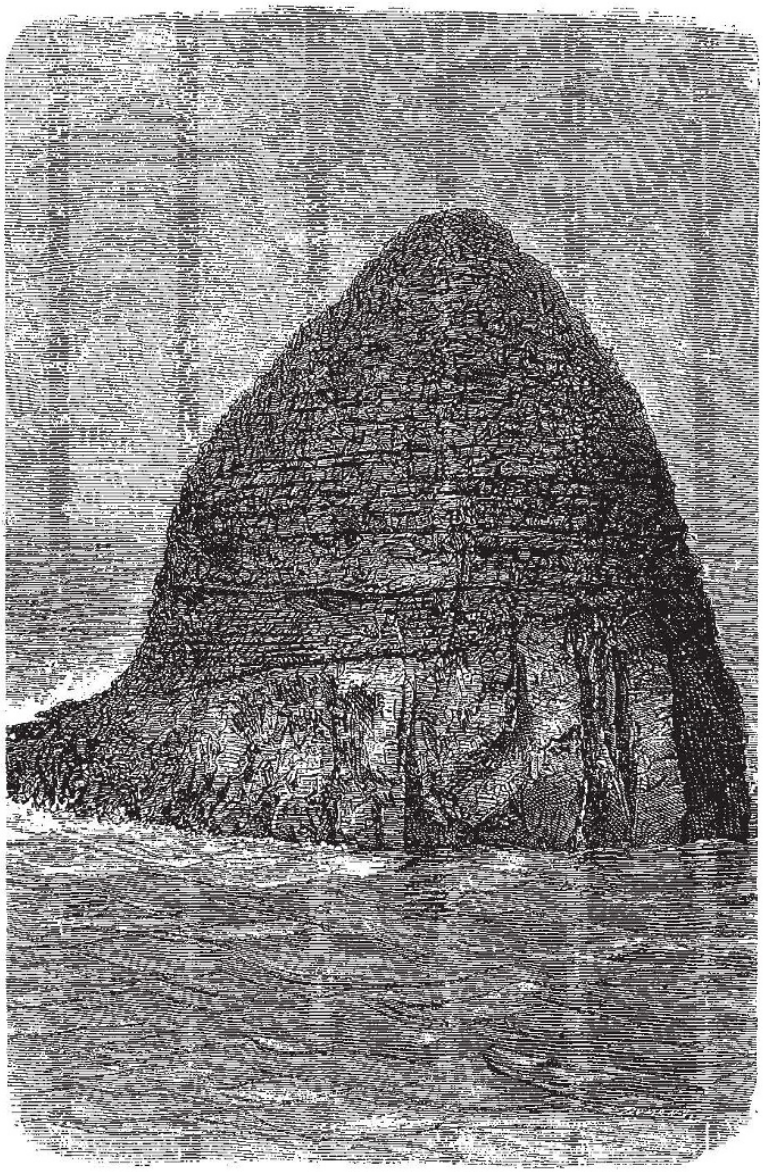

F.G. I.-Ninepin Rock.

pany this notice, which are taken from the original memoir.

If the reader wishes to fix the exact position of these curious islands he has only to trace along the line of lat. $40^{\circ} \mathrm{S}$, and about mid-way in the Southern Ocean between the Cape of Good Hope and Melbourne, near long. $80^{\circ} \mathrm{E}$., he will find them.

Their discovery has been claimed by the Dutch and the Portuguese. Placed just in the grand ocean route for all vessels leaving the Cape for Australia or China, they were doubtless, despite their isolation, long known. The history of our knowledge of them from 1522 to the present day is well, though briefly, written by M. Vélain.

The Novara called at St. Paul in 1857 , and stayed for fourteen days, and we are indebted to Hochstetter for an excellent account of the geology of the island, though 
the weather was so bad at the time that the collections made were not numerous.

In June, I87r, the English frigate Megara was wrecked on this island and most of the 400 souls that were aboard her had to reside on it for over three months.

On September 30, 1874, the mem. bers of the Transit of Venus expedition landed on St. Paul and spent thereon over three months.

Both the islands are essentially volcanic. In 1696 when van Vlaming visited St. Paul, the vast crater occupied its central part, and was above and quite isolated from the sea, and it seems to have been even thus in I754, but at present the sea flows freely into it, and at the place of communication there is a depth of upwards of six feet. It attains a height of about 250 metres and its contour line is not much more than five nautical miles. A little to the north of the entrance to the crater where the sea has broken in there is a wonderful pinnacle of basaltic lava, which receives the name of the Ninepin rock (Fig. I). The rocks composing it are trachitic, of a compact texture, but more or less zoned. These rocks, full of silex, and poured forth in great measure under the sea, exhibit still the traces of the energetic alterations which they underwent, not only at the moment of their emission, but also

after their complete solidification, for they have been traversed since their formation in every way; not only numierous fissures forced up by the impetuous escape of gaseous emanations but by the force of geysers, which latter considerably increased the amount of silex on the rock, and this so much so that the walls of such fissures through the trachy tic rock are formed of a very able solid enamel of silex which is rarely hollow, and all the alkalies have totally disappeared. A microscopical examination shows, amid a highly developed amorphous paste, crystals of felspath, and pyroxene, with notable quantities of silex, amorphous (opal) or crystalline (tridymite); but the lavas of different periods of eruption seem to differ in their compositions.

A wonderful core of basalt columns is to be seen at the little North Island (Fig. 2) which consists of little else than columns, though many of them are now thrown down. Some of the more compact of the lavas present a more or less picturesque outline, as can be seen at Hutchinson Point (Fig. 3), towards the south-east of the island. Their endurable and adhesive glissades could alone furnish such needle-shaped projections as would be capable of resisting the extreme and never-ceasing violence of the seas that beat on them. Along with the basaltic lavas, there will be found here and there on their upper surfaces little cones of scoriæ thrown up from little supplementary volcanoes; sometimes these will be found here and there quite isolated, at other times they will be found forming a ring as it were around the principal crater. They form a record of the fact that long after the great original outburst that formed this island there were numerous smaller eruptions, and that the source of volcanic power endured for a considerable time.

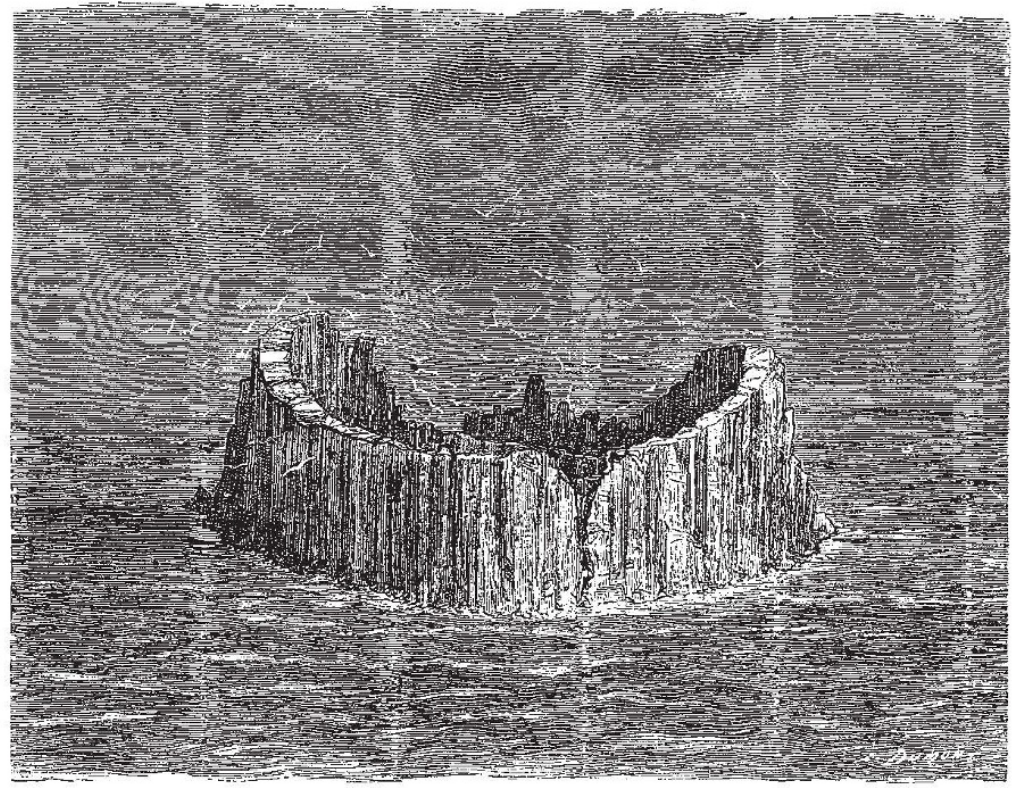

FiG. 2. - North Island.

Although at the period of Lord Macartney's visit (1793), Dr. Gillian remarks that there were spots on the island too warm to walk on, yet there is not a trace of recent volcanic action to be now felt or seen, except in the interior of the crater. M. Vélain informs us that the botanical collec-

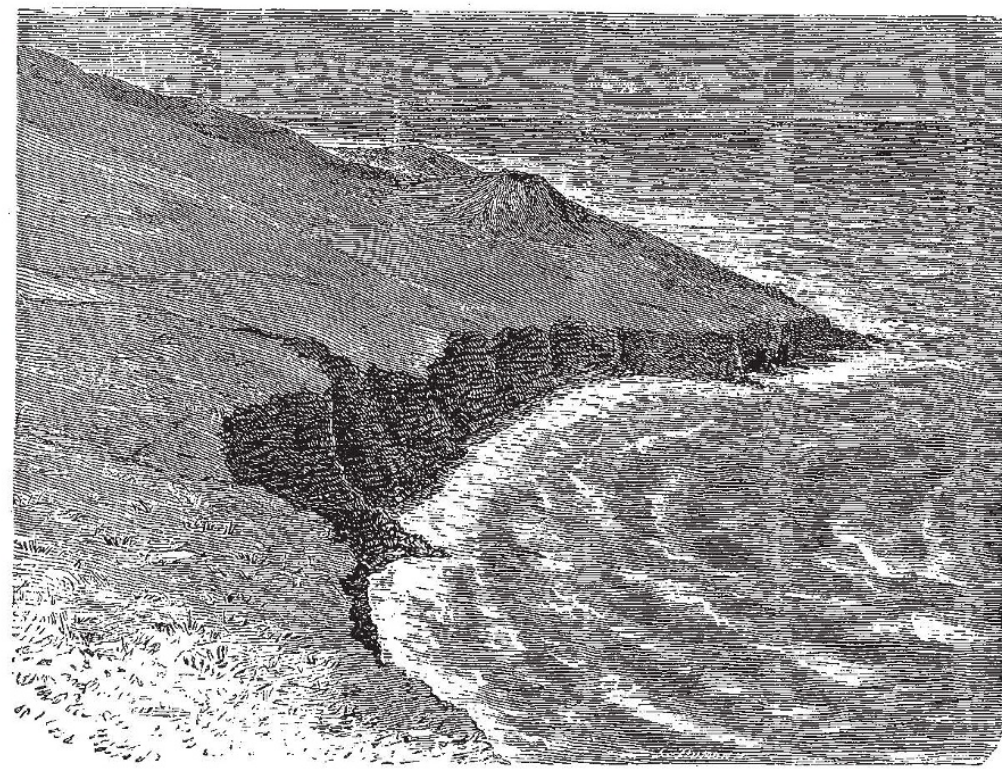

Fıg. 3--Lava Cliffs-Hutchinson Point.

tions made will be fully described by Dr. de l'Isle (from fifty to fifty-five species, not counting algæ, were found), and that the rich and large collections of marine animals, including fish, Crustacea, Echinoderms, Ascidians, Hydro- 
zoa, and Alcyonaria, will be described under the superintendence of Prof. Lacaze Duthiers.

In this present memoir M. Vélain himself gives some most graphic descriptions of the birds that were met with. The little swift seen by Dr. Scherzer, of the Novara, did not turn up, nor were any land birds met with, but the aquatic birds abounded in immense numbers. Among these were the following:-Diomedea exulans, $D$. fuliginasa, D. melanophrys, D. chlororhyncha, Ossifraga gigantea, Procellaria capensis, $P$. cinerea, $P$. hositata, Puffinus aquinoctialis, Stercorarius antarcticus, Prion viitatus, Sterna melanoptera, and last, but by no means

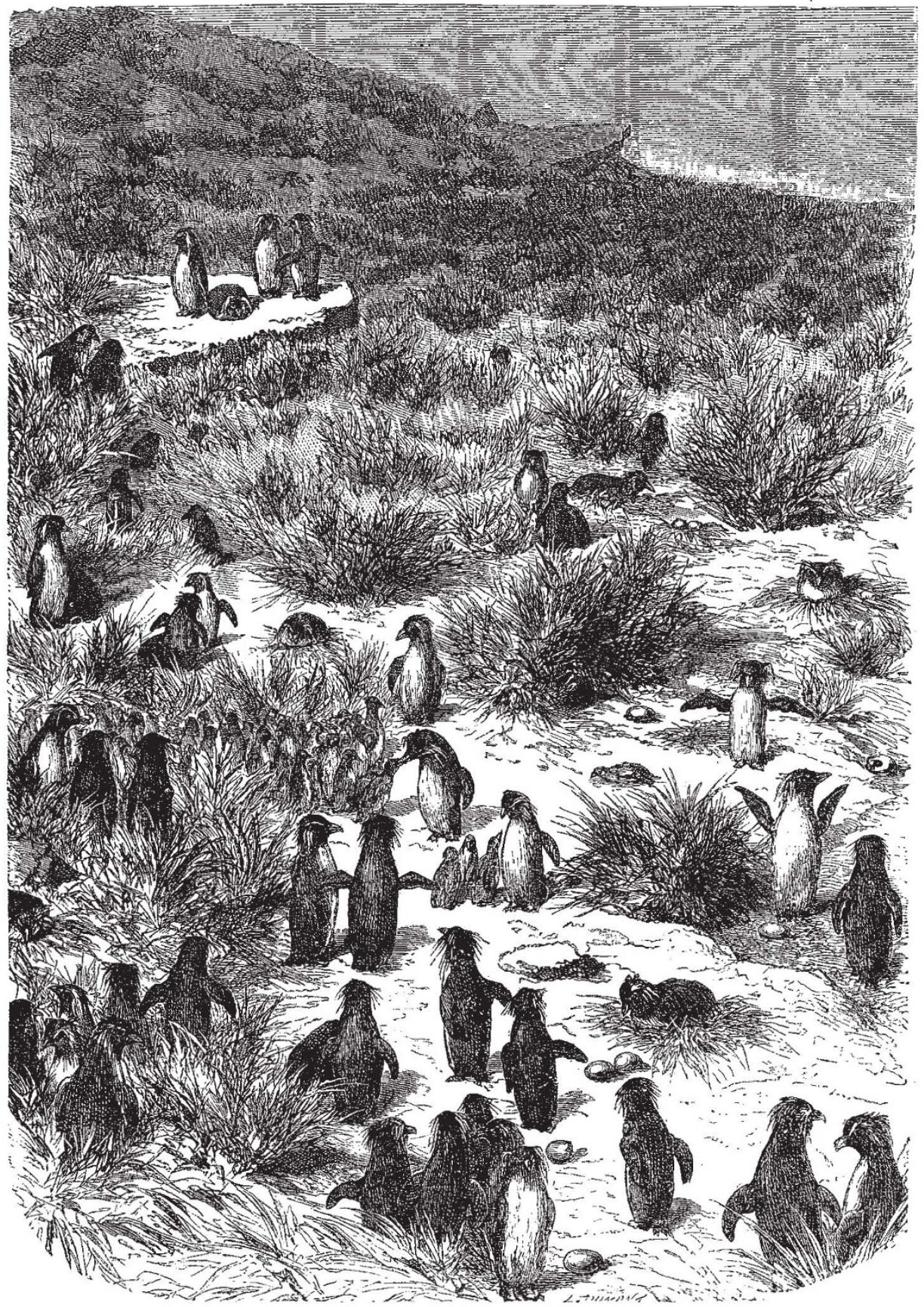

FIG. 4.-Penguins and Young.

the less important, Eudyptes chrysolopha. The history ground seemed alive with them. But it would be imposof these last birds, though often told, is ever strange, and sible, in a few words, to tell the reader all that $M$. Vélain seems always new. In the month of September these has here written about their village life and their infantpenguins began to lay; there were two colonies of them, schools; about their wonderful powers of diving; nor do the larger of which contained millions of the birds; the we wonder that he looks back with no regret to the pleasant 
hours he spent in their midst, and we quite agree with him that such intelligent birds can't merit that nasty English word "stupid."

The accompanying illustration (Fig. 4) will give some slight notion of a nesting station of these interesting birds. At the time of the arrival of the expedition (October) the birds were preparing to hatch ; each pair kept entirely to themselves; each nest had two eggs, large, nearly round, of a dirty white colour, but marked here and there with a few russet spots. Both birds partools of the cares attendant on the incubation, and took turn about on the nest. The bird off duty would at once make for the sea, faithfully. returning at the appointed time, and never failing to waddle direct to its own nest, though no human being could see a difference between the thousands that were strewn about. Sometimes the whole camp of birds would have to be traversed ere the nest sought for would be gained, and a bird trying to make a short cut would be sure to be.attacked by those whom it disturbed, for they are not at all tolerant of one another, and in this they also prove that they are not stupid, for surely neither stupid people nor stupid birds ever quarrel. On M. Vélain arriving in their midst, they would one and all set up an immense, and beyond measure stunning cry, but soon they would calm down, and seem not to mind his presence. The incubation lasted for five weeks. The little ones made their appearance covered all over with a fine close down, and looked like balls of fine grey-coloured wool. They soon got tired of the comforts of their nests, and began to assemble together with their little brothers and sisters of the same colony in large infant schools, which are presided over by some of the sedate old birds. Many times a day, at stated intervals, they are fed, the other portions they spend in sleeping and talking, and a little fighting. Space will not permit us to refer to many curious details about their swimming lessons.

M. Vélain's description of the molluscs of Saint Paul is an important contribution to science; the new species are well illustrated on four plates. As was to be expected, there are forty species of Gasteropods to but nine of Acephala, and there is but a single Brachiopod; no landshells seem to have been found. The cuttle-fish taken are not enumerated, but one gigantic ten-armed species was often alluded to by the fishermen, and at last, as if to prove their assertions true, one morning, after a great storm, a specimen thereof was thrown ashore, and fortunately was at once photographed; unfortunately only its head, arms, and! pen could be preserved. The generic name of Mouchezis (after the commander of the expedition) has been proposed for it. Probably it comes near to Steenstrup's Architeuthis, which it resembles in size, by its having circular-shaped suckers, which were ornamented by a row of fine horny denticulations and by their arrangement on the arms, but from which it differs by the singularly shortened form of the short arms, which presented quite the appearance of having been abruptly tru ncated instead of running out to a more or less tapering point as in most cephalopods; and then the inferior termination of the dorsal ossicle is quite unlike that described by Steenstrup in his genus. Mouchesia SanctiPauti measured from the tip of its longest arms to the end of the body, upwards of twenty-two feet. A species of Ommastrephes swarmed in the adjacent sea and seemed to be the chief food of the penguins.

\section{E. Perceval Wright}

\section{NOTES}

SxSTEMATIC botany has lost one of its greatest living names in the death of Elias Magnus Fries, Emeritus Professor of Botany in the University of Upsala. He was born August I 5, 1794, and died on February 8 inst. His very numerous works, especially on fungi and lichens, give him a position as regards those groups of plants only comparable to that of Linnæus. His services to science were recognised by the Royal Society in his election as a foreign member in 1875 .

The funeral service of M. Claude Bernard took place at Paris, at the public expense, on Saturday, February 16, at St. Sulpice, in presence of an immense assembly. The interment took place at Père-la-Chaise. The chief rnourners were MM. Bardoux, the Minister of Public Instruction, Dumas and Bertrand, Perpetual Secretaries of the Academy of Sciences, Fizeau, President, Mezières, Chancellor of the Academy of Sciences, M. Paul Bert, who is filling the chair of Claude Bernard at the Jardin des Plantes, and Laboulaye. These gentlemen delivered addresses at the grave, which will be published in the Coniptes Rendits and official papers.

From the last report of Dr. Dohrn, the director, we notice that the zoological station at Naples has developed a most remarkable degree of activity, and is becoming a valuable centre of biological research. By the generosity of the Prussian Government it has been provided with a small steamer, and the uninterrupted expeditions in this vessel have secured to the laboratories an enormous and most varied stock of material for research. Dr. Dohrn has carefully organised a plan for the systematic examination of the entire fauna of this part of the sea, to be accompanied by exhaustive descrip. tion. The literary portion of the work will consist of elaborate monographs on all the families and species represented in the Gulf of Naples. They will not be prepared by the members of the station only, but it is hoped to procure the assistance of all familiar with this special department, and the contributions can be in English, French, German, or Italian. Two monographs on the Elenophore and Balanoglossi will appear during the present year, and arrangements have been made for the speedy preparation of eleven others. These will all be based, in regard to nomenclature and classification, on a work shortly to appear under the title, "Prodromus Faune? Mediterraneæ," which will contain a complete abstract of the literature on this subject up to the present time. The details of anatomical and embryological investigation will form the leading feature of the whole work.

Trie Radicals in the French Chamber cannot be accused of opposition to the claims of science. We notice that in a late session a member of the extreme left proposed an amendment to the budget of instruction, which provided for the appropriation of 30,000 francs for an expedition to California to observe the next transit of Mercury, 40,000 for the continuation of the explorations in Northern Africa, where it has been proposed to admit water from the Mediterranean, and 100,000 to enable the Abbé Debès to make a journey across Africa from Zanzibar to the Congo. As the appropriation was granted, we may hope soon to see the latter portion of it carse the appearance of a new rival of Stanley, for the Abbé has had, like Livingstone, invaluable experiences as a missionary, which will enable him to enter upon the undertaking with great promises of success.

THE Astronomical Section of the French Academy has been summoned by the Minister of Instruction to nominate two candidates for the vacant position of the late M. Leverrier.

IN Parisian scientific circles Prof. Charles Friedel is mentioned as the probable successor to the place in the Chemical Section of the Academy rendered vacant by the death of Victor Regnault.

A NEW Archæological Institution at St. Petersburg was opened on January 27 last. The director and founder of the Institution, M. N. W. Katcholoff, delivered the inaugural address, in which he pointed out the importance of the archæological investigation of the great Russian empire, and the great 